\title{
SAÚDE NO TRABALHO DE FUMICULTORES DO RS: NÃO ADOECE SOMENTE QUEM FUMA, MAS TAMBÉM QUEM PLANTA
}

TOBACCO FARMERS' HEALTH AND WORK IN RS: BOTH FARMERS AND SMOKERS GROW SICK SALUD EN EL TRABAJO DE LOS PRODUCTORES DE TABACO EN RS: NO SÓLO ENFERMA QUIEN FUMA, SINO TAMBIÉN QUIEN PLANTA

\author{
Laura Silva Peixoto de Castro* \\ Janine Kieling Monteiro ${ }^{* *}$
}

\begin{abstract}
RESUMO
Este artigo investigou as vivências de sofrimento e como os fumicultores lidam com adversidades no trabalho. Participaram do estudo 15 fumicultores de Dom Feliciano-RS. O instrumento empregado foi a técnica dos grupos focais. No exame dos dados, realizou-se a análise de conteúdo, definindo categorias a priori com base na abordagem teórica da psicodinâmica do trabalho dejouriana. O não reconhecimento, remuneração baixa e instável, condições laborais danosas e sobrecarga de trabalho foram destacados como elementos desencadeadores do sofrimento. Muitos trabalhadores, mesmo cientes da sua exploração, responsabilizam-se individualmente pela maioria dos seus atos: culpam-se por destinarem poucas horas ao descanso e lazer e por seu endividamento. Nesse cenário de precarização desencadeado pela organização do trabalho, os trabalhadores vivenciam desavenças familiares, drogadição, trabalho infantil e suicídio. Evidenciou-se que fumicultores precisam ter "voz" para que seja lançada sua crítica à sociedade e que se apropriem dessa construção reflexiva, a fim de ressignificar seu trabalho.
\end{abstract}

Palavras-chave: Saúde do trabalhador. Sofrimento no trabalho. Fumicultores. Grupo focal. Psicodinâmica do trabalho.

\section{ABSTRACT}

This paper has investigated how tobacco farmers deal with the adversities experienced in work. Fifteen tobacco farmers from Dom Feliciano-RS participated in focus groups. For the results, content analysis was used, defining a priori categories based on the theoretical approach of Dejour's Work Psychodynamics. Four main causes of suffering have been pointed out:

Texto recebido em 17 de agosto de 2013 e aprovado para publicação em 21 de maio de 2015.

* Mestra em Psicologia Clínica pela Universidade do Vale do Rio dos Sinos (Unisinos); psicóloga estatutária no Município de Igrejinha-RS. E-mail: lauracastro81@gmail.com.

** Doutora em Psicologia pela UFRGS; professora nos cursos de Graduação e Pós-Graduação em Psicologia na Unisinos. Endereço: Universidade do Vale do Rio dos Sinos. Programa de Pós-Graduação em Psicologia. Avenida Unisinos, 950 - Bairro Cristo Rei, São Leopoldo-RS, Brasil. CEP: 93022-000. E-mail: janinekm@unisinos.br. 
no acknowledgement, low and unstable income, dangerous work conditions and excessive workload. Despite being aware of the work conditions, many tobacco farmers consider themselves guilty for indedtedness and not dedicating enough time for rest. In this precarious environment instigated the way the work is established, workers experience: family disputes, drug addiction, child labor and suicide. It has become clear that tobacco farmers need a 'voice' so that their opinions can be heard, as well as owning this reflexive construction in order to re-determine their work.

Keywords: Worker health. Suffering at work. Tobacco farmers. Focus group. Work psychodinamics.

\section{RESUMEN}

En este artículo se investigó las experiencias de sufrimiento y cómo los productores de tabaco hacen frente a las adversidades en el trabajo. Los participantes fueron 15 productores de Dom Feliciano-RS. El instrumento utilizado fue la técnica de grupos focales. En el análisis de los datos se llevó a cabo el análisis de contenido, definiendo categorías a priori con base en el enfoque teórico de la psicodinámica del trabajo dejouriana. El no reconocimiento, remuneración baja e inestable, condiciones de trabajo perjudiciales y sobrecarga de trabajo se destacaron como factores desencadenadores del sufrimiento. Muchos trabajadores, aun conscientes de que son explotados, se responsabilizan individualmente por la mayoría de sus actos: ellos se culpabilizan por dedicar pocas horas al descanso y al ocio, y por su endeudamiento. En este escenario de precarización desencadenado por la organización del trabajo, los trabajadores vivencian desavenencias familiares, drogadicción, trabajo infantil y suicidio. Se evidenció que los productores de tabaco deben tener "voz" para que su crítica sea lanzada a la sociedad y para que ellos se apropien de esta construcción reflexiva con el fin de resignificar su trabajo.

Palabras clave: Salud ocupacional. Sufrimiento en el trabajo. Productores de tabaco. Grupos focales. Psicodinámica del trabajo.

\section{INTRODUÇÃO}

Dsta investigação propôs-se a problematizar as vivências de prazer e de sofrimento experimentadas por fumicultores em seu exercício laboral. - 1 Apesar de a literatura ser vasta em retratar os malefícios dos agrotóxicos e da de precarização do trabalho no exercício laboral dos agricultores, poucos são os estudos que contribuem para o entendimento da percepção dos fumicultores, especificamente sobre o seu trabalho. A relevância social deste estudo fundamentase na oportunidade de compreender tais vivências sob a ótica desses trabalhadores, 
visto que raras foram as pesquisas, conforme a revisão de literatura realizada, que buscaram estudar essa perspectiva como objetivo principal.

Trazemos à discussão dois aspectos inerentes ao cultivo do tabaco na contemporaneidade: um negativo e outro positivo. Os fumicultores são alvo de críticas na contemporaneidade, cultivam um produto com valor de venda, mas mundialmente definido como prejudicial à saúde da população e nocivo ao meio ambiente (Vargas \& Oliveira, 2012). Apesar dos malefícios, o plantio de fumo é a principal fonte de renda de $90 \%$ das 190 mil famílias de fumicultores do Rio Grande do Sul (Silva \& Ferreira, 2006).

Para compreender os fatores que acarretam o prazer e o sofrimento desses agricultores, é necessário conhecer as atribuições que têm e suas condições de trabalho. Apesar de o plantio de tabaco ser considerado uma cultura de verão, este compreende atividades o ano todo. As mudas são preparadas no início da primavera, a colheita ocorre no verão e, por fim, é realizada a secagem das folhas, que são classificadas quanto à qualidade e agrupadas em fardos. A produção é ininterrupta: na fase de venda do tabaco, inicia-se o preparo da terra e a coleta de lenha para a safra seguinte (Troian, Oliveira, Darcin, \& Eichler, 2009).

Atualmente um dos problemas mais críticos enfrentados pelos fumicultores é a baixa rentabilidade que o plantio lhes oferece. Segundo Almeida (2005), o retorno econômico auferido pelos agricultores seria bem maior caso as empresas fumageiras não se prevalecessem de seu poder de oligopólio para dominar o mercado de compra e venda do tabaco (Arcury \& Quandt, 2006). A indústria fumageira apenas garante aos agricultores a compra do fumo por eles produzido, mediante a assinatura de um contrato que em nada lhes favorece. Esse acordo marca o início do quadro de exploração pactuado entre o produtor e a companhia de tabaco (Almeida, 2005).

O fumicultor é o elo mais frágil da cadeia produtiva. O sofrimento que experimenta é reflexo da exploração e da precarização do trabalho. Há estudos que apontam os riscos à saúde aos quais esses trabalhadores estão expostos, explicando que a intensificação da atividade laborativa favorece o seu adoecimento físico. No entanto estas investigaçóes pouco esclarecem sobre os fatores de sofrimento ou adoecimento psíquicos experimentados por esses trabalhadores.

Destacam-se na literatura, por exemplo, investigações apontando os malefícios da excessiva exposição dos agricultores aos agrotóxicos (Peres \& Moreira, 2003; Rocha Júnior, Botelho, Fiol, \& Oshima-Franco, 2004; Schmitt, Schmitt, Kouimintzis, \& Kirch, 2007; Troian \& Eichler, 2009; Troian et al., 2009). 
Outras pesquisas explicam que os fumicultores estão suscetíveis também aos riscos físicos causados pelo calor, vento, frio, chuva e radiação solar (Heemann, 2009). Essas condiçôes de trabalho podem lhes acarretar câimbras, fadiga, insolação, resfriados, afecção das vias aéreas superiores e câncer de pele. Problemas respiratórios são comuns devido ao contato a elevados níveis de pó de tabaco em algumas etapas do ciclo produtivo e durante a queima e preparação dos fardos de fumo para a venda (Arcury \& Quandt, 2006). Ademais, o movimento de baixar e levantar seguidamente para colher o tabaco prejudica a região lombar, os braços, as mãos e pulsos, em decorrência do esforço repetitivo (Fialho, 2003; Heemann, 2009).

A sobrecarga de trabalho que é experimentada no corpo destes trabalhadores não é o único fator de seu sofrimento. Há também a preocupação com as dívidas. Muitos fumicultores ficam impossibilitados de pagá-las ao credor, geralmente à empresa, pessoa jurídica com a qual costumam contratar empréstimos para adquirir insumos e outros materiais necessários à produção, além de bens móveis, como tratores, carros e motos (Almeida, 2005; Silva, 2007).

Uma vez endividado, são frequentes as críticas dos familiares, amigos e vizinhos dirigidas ao produtor, sendo avaliado como preguiçoso e incapaz de cumprir com seus deveres. Sua honra e credibilidade passam a ser questionadas. O endividamento, nesses casos, torna-se um "balizador das relaçôes sociais" (Silva, 2007, p. 116).

Ademais, o excesso de atividades e responsabilidades inviabilizam o repouso dos fumicultores. No dia a dia, o lazer dos fumicultores é assistir à televisão e ler o jornal, caso não estejam muito cansados, o que é raro (Fialho, 2003). Segundo a autora, os produtores de tabaco descrevem sentir mais desprazer do que prazer em seu exercício profissional. A investigação da autora perpassou a proposta de descrever os malefícios do plantio do fumo à saúde dos trabalhadores, visou à compreensão do sentido do trabalho para os fumicultores, sendo o estudo que mais se aproximou do objetivo desta pesquisa dentre o rol de trabalhos apreciados na revisão de literatura.

Diante do contexto exposto, este estudo tem como objetivo principal investigar as vivências de sofrimento no trabalho e como os fumicultores lidam com as adversidades em seu exercício, como exposição a fatores de risco à saúde, intensificação do trabalho e endividamento. O estudo pretende compreender os fatores de sofrimento que, muitas vezes, antecedem o adoecimento psíquico. Objetiva-se também a desvelar se o prazer no trabalho nesse plantio é, de fato, pouco experimentado e por quê. 


\section{MÉTODO}

\subsection{Delineamento}

Esta pesquisa foi desenvolvida com base em uma perspectiva qualitativa, a fim de compreender o fenômeno estudado em sua complexidade. Segundo Heloani e Lancman (2004), é adequado empregar a abordagem qualitativa quando se objetiva a compreensão de um fenômeno em sua totalidade, no intuito de desvelar como as pessoas o significam. Aos que participaram deste estudo oportunizouse um momento de troca, de fala e de escuta, favorecendo não apenas a sua reflexão acerca das vivências relacionadas ao seu exercício laboral, mas também um espaço de discussão capaz de promover a mobilização do coletivo (Martins \& Mendes, 2012; Merlo \& Mendes, 2007; Heloani \& Lancman, 2004).

\subsection{Participantes}

Participaram deste estudo 15 fumicultores, homens e mulheres, entre 19 e 44 anos, com ensino fundamental incompleto. Foram adotados os seguintes critérios de inclusão/exclusão: ter mais de 18 anos, residir no Município de Dom Feliciano-RS, cultivar o fumo como sua principal fonte de renda e ter experiência nesse plantio de, no mínimo, duas safras. Segundo os dados do Instituto Brasileiro de Geografia e Estatística (IBGE, 2010), a população de Dom Feliciano-RS compreende 14.380 habitantes, sendo que 11.046 munícipes residem na área rural. Ademais, conforme o Instituto Nacional de Câncer (INCA) (2010), o cultivo do fumo é responsável por $86,5 \%$ do produto interno bruto (PIB) agrícola do Município, que está entre os dez maiores produtores de tabaco do País. Ressalta-se que a maioria dos participantes começou a trabalhar na infância, em família, e o que começou mais cedo tinha 6 anos à época.

Para a coleta de dados, utilizou-se da técnica de grupos focais (Trad, 2009), sendo realizados dois grupos: um com 7 e outro com 8 fumicultores, havendo um encontro com cada grupo. Buscou-se incentivar os participantes a ressignificarem sua experiência profissional diária, tornando visíveis o seu prazer e o seu sofrimento no trabalho (Merlo \& Mendes, 2007).

\subsection{Procedimentos éticos e de pesquisa}

Este projeto de pesquisa foi aprovado pelo Comitê de Ética em Pesquisa da Universidade do Vale do Rio dos Sinos (UNISINOS). Foram seguidos todos os procedimentos éticos que regulamentam pesquisas com seres humanos, em conformidade com a Resolução 16/2000 do Conselho Federal de Psicologia 
(CFP) e com a Resolução 196/96 do Conselho Nacional de Saúde (CNS). A pesquisadora, no início dos encontros, fez a leitura do termo de consentimento livre e esclarecido (TCLE), explicando aos participantes os objetivos e procedimentos a serem seguidos. As entrevistas foram transcritas na íntegra e salvas em arquivos de áudio (no formato MP3). Para a publicação dos resultados, optou-se por caracterizar o grupo de trabalhadores, em vez de descrevê-los individualmente, impedindo a identificação dos participantes (Merlo \& Mendes, 2007).

\subsection{Procedimentos de coleta de dados}

Para a realização da coleta de dados, a pesquisadora solicitou ao Sindicato dos Trabalhadores na Agricultura Familiar (SINTRAF) uma lista com os nomes e com os telefones dos seus associados para realizar a seleção amostral. Os fumicultores contatados através dessa lista foram selecionados por acessibilidade ou por conveniência, sendo o convite para participação no estudo feito àqueles que tinham interesse e disponibilidade e que preenchiam os critérios de inclusão/ exclusão. Entre os fumicultores contatados, alguns indicaram outros trabalhadores que também poderiam participar. $\mathrm{O}$ convite foi estendido também a estes, prática que corresponde ao método de seleção de participantes definido como snowball ou "bola de neve" (Biernacki \& Waldorf, 1981), complementarmente utilizado nesta pesquisa.

Conforme a disponibilidade dos fumicultores, agendou-se, entre os meses de março e abril de 2012, a data e a hora dos encontros, ocorridos em espaços reservados e amplos. As despesas com o deslocamento/transporte foram custeadas pela pesquisadora, assim como oferecido um lanche aos agricultores, seguindo as orientações de Trad (2009).

\subsection{Procedimentos de análise dos dados}

Para os procedimentos de análise dos dados, optou-se pela análise de conteúdo conforme Bardin (1994), sendo os encontros dos grupos focais transcritos na íntegra (sem correçôes ortográficas ou gramaticais). Realizou-se a triangulação metodológica entre a psicodinâmica do trabalho (PDT) dejouriana, grupo focal e análise de conteúdo, sendo estabelecidas três categorias a priori: "organização do trabalho na fumicultura", "sofrimento no trabalho" e "prazer no trabalho". Os conceitos teóricos da abordagem da PDT foram apresentados e problematizados ao longo do texto, conforme foram relacionados aos resultados obtidos. 


\section{RESULTADOS}

Para apresentar os resultados levantados nesta investigação, foram atribuídos nomes fantasia aos participantes: Sônia, Maria, Leonardo, Daniel, Luís, João e Paulo (grupo A); e Rafael, Gustavo, Solange, Fátima, Patrícia, Carlos, Pedro e Claudete (grupo B). Os dados elucidados a seguir permitiram conhecer a perspectiva dos fumicultores acerca de como a organização do trabalho na fumicultura pode favorecer o prazer e o sofrimento no trabalho, bem como adoecimento como consequência das vivências de sofrimento.

\subsection{A organização do trabalho na fumicultura}

De acordo com a PDT, a organização do trabalho caracteriza o trabalho em diversos aspectos, podendo ser estes positivos ou negativos ao trabalhador. Nesse sentido, a organização do trabalho pode favorecer tanto a vivência de prazer quanto de sofrimento psíquico. Entre os aspectos relacionados à organização do trabalho estão o status social da atividade desenvolvida; as condiçôes em que o trabalho é realizado; o modo como o sujeito se apropria do seu trabalho; o modo como o indivíduo é incentivado a desempenhá-lo; o manejo do sistema e poder hierárquico para manter sua ordem, sua direção e sua hierarquia, fiscalizando e controlando os trabalhadores; os aspectos afetivos e relacionais implicados no posto de trabalho ocupado; o grau de iniciativa e autonomia do trabalhador sobre as tarefas; e a possibilidade de cooperação e comunicação no trabalho (Dejours, 1992, 2007).

Tendo em vista que compreender como ocorre a organização do trabalho na fumicultura abre caminhos para identificar os fatores de prazer e de sofrimento no trabalho, esse foi o primeiro assunto debatido nos grupos. A proposta era iniciar a discussão incentivando os participantes a verbalizarem e a trocarem ideias acerca de um tema que lhes fosse comum: explicar como se desenvolve o plantio do tabaco.

Os participantes apontaram que, na fumicultura, as atividades são previamente definidas, sendo algumas realizadas por todos os membros da família e outras executadas em duplas. As atividades insalubres, como o trabalho realizado na estufa, a aplicação de agrotóxicos e a coleta e transporte manual de lenha para abastecer as fornalhas onde se queima o fumo são geralmente desempenhadas por adultos, evitando o envolvimento das crianças e, em alguns casos, o das mulheres.

Esses dados correspondem aos descritos nas pesquisas desenvolvidas por Schlindwein (2010) e Heemann (2009), em que os fumicultores mencionaram 
a participação de todo o grupo familiar na produção, sendo os papéis de cada membro do grupo familiar bem definidos. As fumicultoras felicianenses mencionaram não desenvolver trabalhos leves, mas um número de atividades e de responsabilidades maior se comparado ao de outra pessoa da família. Além de trabalharem na agricultura, elas têm atribuições domésticas, precisam cuidar da casa e dos filhos.

O marido: vamo, vamo mulher! E nós temos que ir junto. Pega na enxada né, plantando, né, [...] chega 11 horas a gente vai pra casa, fazê almoço e aqui a gente começa, né. Aí a lida do almoço, leva as crianças no colégio, aí deita um pouquinho né, descansa, a gente somos sofridas, né (Sônia).

Outra questão que emergiu em ambos os grupos foi o trabalho infantil. Alguns produtores que têm filhos menores de 18 anos disseram que estes trabalham tanto quanto os adultos. A temática do trabalho infantil preocupa os fumicultores, que referiram estar cientes de que o melhor seria que os filhos pudessem apenas estudar, mas que, na agricultura familiar, isso nem sempre é possível. Uma agricultora mencionou que a maioria dos universitários felicianenes que estudam e residem fora da cidade retornam ao Município no período de férias acadêmicas para trabalhar na fumicultura e garantir, dessa forma, a continuidade de seus estudos. Alguns participantes referiram que trabalhar nas lavouras desde a infância é um mal necessário, pois os jovens das áreas rurais pouco dispõem de recursos para realizar qualificações profissionais alternativas à agricultura. "Vai, sai da roça, consegue um emprego na cidade, de que jeito?” (Fátima).

Portanto a fumicultura é uma modalidade de cultivo basicamente artesanal, em que o local de trabalho é a própria morada, e os colegas de serviço, os familiares (Hillesheim, 2001). O trabalho infantil, característico na produção do tabaco, é algo naturalizado culturalmente entre os produtores e também uma questão transgeracional: os pais permitem que os filhos trabalhem porque foram ensinados e incentivados a trabalhar desde a infância. As famílias necessitam da "ajuda" das crianças durante a colheita, colocando a saúde destas em risco, comprometendo o seu desenvolvimento e o seu futuro. A falta de garantia de lucro com a safra impede as famílias de dispensarem a mão de obra infantil, sendo, na maior parte dos casos, financeiramente inviável a contratação de profissionais fumicultores para auxiliar no ciclo produtivo (Biolchi, 2005).

O desdobramento da discussão incitou os participantes a discorrerem sobre os papéis do grupo familiar nesse cultivo, levando-os a discorrer sobre o sofrimento acarretado pela necessidade do trabalho infantil e pela sobrecarga de trabalho feminino. A organização do trabalho na perspectiva desses agricultores apresentou-se como um potencial desencadeador de sofrimento: o modo como 
os participantes se apropriam do seu trabalho aparece como sendo a única possibilidade que vislumbra para a mantença das famílias, parece não haver, para esses fumicultores, alternativa que não seja trabalhar intensamente no plantio do tabaco. O trabalho é significado como uma obrigação diária imprescindível e exaustiva: uma condição de status no trabalho que os fumicultores aprendem como estagnada desde a infância. Como os dois grupos apresentavam-se ansiosos para revelar outros anseios e tristezas inerentes ao seu cotidiano, a pesquisadora optou por realizar o seguinte questionamento: "O que pode ser considerado ruim ou penoso no trabalho de vocês?".

\subsection{Sofrimento no trabalho}

Anteriormente foi esclarecido que, para a PDT, a organização do trabalho pode favorecer o sofrimento dos trabalhadores. Faz-se necessário explicar também em que momento o sofrimento começa a ser experimentado pelo sujeito. Isso ocorre quando o contexto do trabalho confronta os desejos e vontades do trabalhador: o aparelho psíquico é tensionado, uma vez que algumas pulsões não são satisfeitas (Dejours, 2004; Heloani \& Capitão, 2003; Martins, 2009). O destino dessas pulsões não satisfeitas é o corpo. É neste que o trabalhador experiencia de forma única, subjetiva e singular, o seu sofrimento (Dejours \& Abdoucheli, 1993). Em certo momento, o sofrimento sentido pelo corpo mobiliza o sujeito a dar um sentido e um destino àquele sofrimento. É quando o trabalhador, agente transformador daquilo que experimenta, define, geralmente de modo inconsciente, quais ações serão tomadas em relação a seu sofrimento: aceitá-lo, negá-lo, mantê-lo, suportá-lo, combatê-lo ou controlá-lo (Martins, 2009; Vasconcelos \& Faria, 2008, Dejours, 2004).

\subsubsection{O reconhecimento no trabalho}

Nesta pesquisa, o primeiro fator de sofrimento descrito pelos fumicultores foi a incerteza quanto ao retorno financeiro do plantio, pois consideram que esta lhes acarreta ansiedade e preocupaçôes constantes. Os agricultores mencionaram que é longo o período de expectativa acerca do valor a ser recebido pelo trabalho empregado em toda uma safra, mas extremamente breve o momento em que este valor é definido. A quantia a ser paga ao fumicultor é acertada no ato da venda do fumo, quando o comprador da empresa barateia indevidamente os fardos de fumo, avaliando-os e classificando-os com uma qualidade inferior.

$\mathrm{Na}$ percepção dos fumicultores, essa é uma medida de exploração. A desvalorização do produto não é sentida apenas no bolso do produtor. Acarretamlhes sofrimento, crises de ansiedade e dificuldades para dormir. 
Os agricultores revelaram que, quando não recebem o valor que consideram justo no ato da venda do tabaco, vivenciam a falta de reconhecimento no trabalho, causando-lhes a sensação de perda de sentido de todo o esforço empregado. "Muito suor derramado por nada" (Gustavo). O reconhecimento no trabalho para a PDT é um elemento social da organização do trabalho e um fator determinante para as vivências de prazer do trabalhador: pode advir das chefias ou dos pares. Está relacionado a habilidades para avaliar e julgar a "beleza" e a singularidade do trabalho desenvolvido, por essa razão, trata-se do reconhecimento mais importante e significativo para o trabalhador (Dejours, Abdoucheli, \& Jayet, 1993).

\subsubsection{O sofrimento relacionado a intempéries que podem comprometer a safra, ocasionando o prejuízo}

Alguns fumicultores explicaram que sua ansiedade está relacionada à possibilidade da perda total ou parcial da safra, em decorrência de fatores climáticos e naturais, como chuvas de granizo ou às pragas do fumo, desencadeando o sofrimento dos produtores. "Se há uma nuvem feia lá, ai tu já tá se agarrando com Deus, pedindo a Deus que não venha" (Fátima). Essa participante explicou que o que lhe resta é recorrer às preces, pois o seguro da Associação dos Fumicultores do Brasil (Afulbra), que é obrigada a contratar por meio da empresa, nunca cobriu ou cobrirá o valor do prejuízo causado pelas intempéries.

Outra agricultora mencionou um momento em que vivenciou intenso sofrimento pela perda de toda uma safra de fumo devido a uma chuva de granizo:

Teve um dia aí [...], eu saí pra Dom Feliciano. Tava tudo bem, assim, o fumo muito bonito, o meu fumo que eu plantei. [...] Aí, quando vê, o tempo muda; aí vem um temporal de pedra, a coisa mais triste do mundo. E nós, terra arrendada, nada era nosso, tudo dívida por pagar, pedido todo por pagar e tudo, o fumo virou em nada (Maria).

\subsubsection{Intensificação do trabalho relacionada ao adoecimento físico: uma medida para garantir o lucro}

Outro fator de sofrimento associado à incerteza de retorno financeiro são as condições laborais. Os participantes explicaram que precisam intensificar o trabalho devido à impossibilidade de contratar mão de obra especializada e de adquirirem certos equipamentos para o plantio. Isso porque não têm garantia de que poderão pagar pelos serviços prestados e pelos bens adquiridos. Por essa razão, os fumicultores sujeitam-se à sobrecarga de trabalho, inclusive a intensas jornadas. São comuns as lesões na coluna devido à necessidade de agachamento 
constante e por esforço repetitivo com as mãos e ombros, pois não há máquina para colher fardos de fumo. O produtor o colhe acaçapado e vai acomodando as folhas de tabaco sob os braços ou sobre um carrinho. "Meu problema é nos nervos das mão [...] atingiu a bursite de forcejar" (Claudete). "Você vai ver nos boletins das pessoas, a maioria é coluna, tendinite e a bursite"(Daniel). "Problema na coluna, eu acho que não tem um produtor que não tenha" (Rafael).

A etapa de secagem do fumo também acarreta o adoecimento físico. Para abastecer a fornalha, os fumicultores deixam suas camas durante a madrugada e vão em direção ao paiol. Essa tarefa lhes expõem a mudanças climáticas bruscas, do calor para o frio e o contrário.

Cuidar fogo é o pior que tem pra saúde: estraga a saúde. Olha aqui, ó, o resultado, tá em mim agora, neste instante, tô sofrendo aqui. Tenho ameaça de paralisia do calor, tipo assim, vai do calor pro frio [...] Tô com os carrinho (mandíbula) duro. Peguei tipo de uma infecção, deu nas glândulas, tudo (Leonardo).

Esses dias, eu tava dormindo bem tranquilo lá de noite, né, no quentinho. Aí o cara acorda lá no meio da noite, sai no frio, pra ir lá pra estufa [...] E isso não é uma vez na semana $[\ldots]$, às vezes, acordar quatro vezes numa noite (Daniel).

Pelos relatos, fica claro que esses trabalhadores não vislumbram alternativas para evitar os malefícios à coluna e respiratórios. No entanto os fumicultores verbalizaram que poderiam diminuir o uso de agrotóxicos nas lavouras, preservando sua saúde, mas que isso não acontece. Devido à busca pela estabilidade financeira, o agricultor expóe-se ao risco do adoecimento e não evita o uso dos agrotóxicos, pelo contrário, emprega-os ainda mais para garantir seu lucro.

Usemo tudo em excesso, tudo em excesso, [...] o certo do Karatê (agrotóxico) é colocar $25 \mathrm{~mL}$ [...], mas se a gente bota $25 \mathrm{com}$ a pulga tomando conta, ah vamo usar 50 porque aí, porque aí $50 \mathrm{~mL}$ vai olhando pra trás e a pulga vai ficando morta. Aí, na outra semana, quando vai colher fumo, a comichão (coceira) no couro (pele) é danada [...] Tá caindo o coro do cara; $50 \mathrm{~mL}$. Bota 25 , que não vai dar aquele comichão tão forte, vai dar comichãozinha [...]. O Karatê é um veneno proibido, a gente não pode e a gente usa ele sabendo que é proibido (Leonardo).

Outro produtor explicou que os envenenamentos são constantes. "Eu acho que envenenado a gente tá sempre. Eu acho que tu tando nessa, nessa função aí do fumo, tu tá envenenado direto" (Rafael).

Interessante destacar que o envenenamento se tornou algo rotineiro, aceitável pelos agricultores. Um dos fumicultores, apesar de ter se intoxicado cinco ou seis 
vezes, considerou esse número de intoxicações pouco expressivo. "Umas cinco ou seis vêiz só, mas isso em 10,15 anos" (Paulo). Outro fato curioso é que alguns fumicultores que sofreram de intoxicação uma única vez afirmaram ter adquirido uma imunidade vitalícia após o tratamento de saúde.

Eu já tive intoxicado [...]. Tive dois dia baixado no hospital [...]. Isso aí faz uns vinte e poucos anos, nunca mais eu sei o que é vomitar na minha vida. Que o medicamento ficou, o tratamento foi certinho pra aquele problema, nunca mais (Gustavo).

Eu foi um pouquinho [...] tirei uma semana fora do fumo, tomando uns remédio, depois melhorei. Nunca mais me deu mais nada daquilo" (Claudete).

Um agricultor disse nunca ter se intoxicado, apesar de aplicar o veneno há anos. "Nunca fui intoxicado, aplico veneno faz anos já. Com 10 anos, eu já botava com 15 litro, aí conforme fui crescendo, fui botando com 20 e até hoje. Não me faz mal o cheiro do veneno, até gosto de botar" (Pedro).

Os participantes apontaram que os efeitos deletérios da intoxicação por agrotóxicos poderiam ser minimizados caso os trabalhadores os aplicassem nos horários recomendados, evitando excessiva exposição ao sol, pois conseguiriam suportar o calor e utilizar os equipamentos de proteção individual (EPI): máscara, botas e macacão, considerados desconfortáveis e sufocantes. "Se usar dentro do horário de usar, na parte da manhã, na hora fresquinha, de tardezinha [...], não vai te prejudicar [...]. Todo mundo acha que é o fumo que traz a doença: não é, a doença quem traz é nóis, nóis que procuremo" (Leonardo). "É porque se atracam que nem louco" (Daniel).

Essa foi uma percepção trazida por alguns participantes. Identificaram cometer excessos e, no que se refere ao uso de agrotóxicos, culparam-se por "buscarem a doença”, ao priorizarem o retorno financeiro, o qual é mais garantido com o emprego do veneno, em detrimento da sua saúde e segurança.

Para a PDT, o ato de atribuir exclusivamente a si o risco que o labor oferece ao sujeito é um mecanismo de negação da inquestionável precarização das condições de trabalho. A culpabilização, o descaso com a saúde, os "excessos" e os "erros" descritos pelos fumicultores, podem ser entendidos como reflexo dessa ideologia defensiva por eles construída. Nesse caso, o fumicultor culpa-se diretamente por causar o seu envenenamento, mas não reflete sobre o quanto a organização do trabalho favorece essa atitude. A imunidade vitalícia ao envenenamento, apontada por alguns participantes, provavelmente é uma crença desenvolvida inconscientemente para negar o risco ao qual estão constantemente expostos. Sofrem menos ao acreditarem que dominam o perigo inerente ao seu trabalho, 
em vez de perceberem-se a este condicionados (Dejours \& Abdoucheli, 1993).

\subsubsection{Conflitivas familiares}

A preocupação com a rentabilidade, que leva os fumicultores a cometerem excessos e a se culparem, também acarreta crises familiares, sendo estas definidas como desencadeadoras de sofrimento pelos fumicultores. Segundo os participantes, quando o marido vende o fumo a um baixo valor, são frequentes as desavenças familiares, pois a mulher culpa o homem.

Minha esposa tá junto ali se arrebentando junto comigo, aí eu agarro e não vendo bem o fumo. Alguma coisa ela vai me reclamar, que queria uma coisa e eu não pude dar (Rafael).

Em casa, mulher e homem já não se olham um pro outro [...] Quem sofre mesmo é as crianças [...]. Quando tem briga, o homem já sai pra lá encher o cano ali adiante (para alcoolizar-se) (Leonardo).

Nessas situações, é comum que o marido agrida fisicamente a mulher e procure alcoolizar-se, numa tentativa de anular o seu sofrimento e esquecer os problemas financeiros e familiares. "Ai o homem bate na esposa. Ai bebe, volta pra casa, aí a mulher não quer deixar o homem entrar dentro de casa [...] e ainda apanha do marido" (Maria). Os fumicultores descreveram que são frequentes as desavenças e o afastamento do casal devido ao excesso de trabalho, favorecendo, inclusive, relacionamentos extraconjugais. "A gente chega à noite, não tem vontade de dar um carinho pro marido, vamo deitar e dormir, né?" (Sônia). "Agora um exemplo, um exemplo, não tem outra pessoa pra mim descarregar a raiva, a unica que eu enxergo na minha frente é a mulher" (Leonardo).

\subsubsection{Mecanismos defensivos utilizados}

Conforme mencionado anteriormente, segundo a PDT, dependendo da rigidez da organização do trabalho, o sujeito pode utilizar mecanismos defensivos, estratégias de defesa como uma medida para controlar o sofrimento inevitável, uma possibilidade de manter-se saudável e prevenir a descompensação psíquica (Santos Junior, Mendes \& Araújo, 2009). Em contrapartida, essas estratégias também podem prejudicar o trabalhador, uma vez que ele se adéqua à rigidez da organização do trabalho e o sofrimento se mantém, tornando-se patogênico, num processo de alienação que leva, inevitavelmente, ao adoecimento (Martins \& Mendes, 2012; Mendes \& Araújo, 2011; Dejours \& Abdoucheli, 1994).

Alguns trabalhadores adéquam-se à rigidez da organização do trabalho ao 
aumentar sua plantação, para aumentar os lucros, a fim compensar o baixo valor pago pela fumageira por seu tabaco. "Quem depende de comprar um trator, comprar terra, comprar uma estufa [...] tem que trabalhar em excesso pra pagar as contas" (Daniel).

Um agricultor relatou que costuma fumar excessivamente para se acalmar, tentando amenizar as consequências do excesso de trabalho e das preocupações financeiras com o plantio. Trata-se de um mecanismo defensivo empregado para suportar o sofrimento decorrente do trabalho.

Eu não tenho vício de cigarro, mas conforme o nervosismo [...] é planta lá na lavora pra colher e eu não tenho dinheiro pra bota. Aí é cigarro, um depois do outro [...], tudo em excesso [...], fumando tudo com o nervosismo [...], me drogo e drogado fico, não é só eu. Várias pessoas que não sabem o que fazer; tá nervoso, é aquele movimento todo ali, é fumo pra colher, pra acalmar, achando que o cigarro acalma, o cigarro vai terminando cada vez mais (Leonardo).

Algumas verbalizações deixaram claro que o abuso de álcool é outra das alternativas empregadas para amenizar o sofrimento. "Tomam pra ver se conseguem aguentar o serviço" (Fátima). O consumo de cachaça foi apontado pelos participantes como uma prática habitual entre os fumicultores da região. "A cachaça na realidade é o 'hobby' do povo" (Rafael).

\subsubsection{O suicídio: um ato de desespero}

Alguns fumicultores apontaram que o endividamento dos produtores leva-os ao desespero, motivando-os a se enforcarem.

E a pessoa chega ao extremo, ao desespero. Que teve muitos, não é um nem dois. Se for procurar o histórico do Município, vai ver que várias pessoas já se mataram (Fátima).

Lá em casa, já não morreu um vizinho porque o pai chegou e explicou o que era pra ele fazê, porque senão ele já tinha oh, a cordinha. A gente aconselhou que ele não fizesse por causa dos filhos dele, que ele tem pra criar, por causa das contas (Claudete).

Na percepção de alguns fumicultores, aqueles que se suicidam em decorrência do endividamento são culpados, pois foram impulsivos e ambiciosos ao decidirem plantar uma quantidade superior àquela que poderiam colher.

O suicídio mencionado pelos participantes está, portanto, diretamente associado ao endividamento dos produtores. Para Dejours e Bègue (2009), o suicídio no trabalho não deve ser um ato culpável, pois se trata de um manifesto 
de acusação realizado pelo trabalhador, a fim de sinalizar a precarização no trabalho e a falta de sentido na vida do trabalhador. A culpabilização do suicídio por endividamento descrita neste estudo também pode ser entendida como uma idealização defensiva. Talvez seja mais fácil para os fumicultores julgarem e responsabilizarem individualmente aqueles que se suicidam por não suportarem as adversidades do que perceberem que esse adoecimento psíquico é decorrente da exploração que experimentam.

Os dados obtidos com base nesses apontamentos explicam outra razão para o suicídio de agricultores, diferente daquelas mencionadas em outros estudos: em que o suicídio é relacionado adoecimento psíquico do trabalhador devido a sua exposição frequente aos agrotóxicos (Faria, Facchini, Fassa \& Tomasi, 2001; Pires, Caldas \& Recena, 2005).

\subsection{Prazer no trabalho}

No intuito de compreender se as vivências prazerosas no trabalho estavam apenas relacionadas à rentabilidade da produção, a pesquisadora realizou a seguinte pergunta: "Então esse é o bom do fumo, é quando dá lucro?". Nesse momento, alguns participantes validaram sua afirmativa anterior: "É, esse é o bom do fumo, só" (Rafael).

Em contrapartida, outros fumicultores mencionaram momentos prazerosos: "Dá prazer quando tu chega na lavoura e vê o fumo bonito e tudo" (Fátima). "Adoro coiê com chuva, pode tá chovendo, não dá nada" (Claudete). "Eu gosto muito de planta fumo e gosto muito de classificar fumo" (Maria). "Eu já gosto, vou pra lavoura, pego uma capinadeira [...], o cara vai passa uma enxadinha no fumo: $\hat{o}$ coisa bem boa!" (Daniel).

Observou-se que, pelo fato de as vivências de sofrimento serem mais experimentadas, torna-se difícil aos trabalhadores descreverem o prazer no trabalho. Resistem em elucidar sobre sua satisfação. Prevaleceu a ideia de que o prazer nessa atividade está muito mais associado à ideia de ausência de injustiça e de retorno financeiro do que atrelado a uma experiência de realização pessoal.

Eu acho que o bom do serviço do fumo é o início, né [...]. Tá todo mundo plantando com a esperança de coiê bem, de vendê bem, então até ali todo mundo trabalha com coragem [...]. Aí, dali em diante, pode vir as incomodação, as pestes do fumo, ou é complicação na colheita, ou é vende mal. Então o bom mesmo é a plantação, prepará. Prepará a terra, botá adubo na terra, planta mudinha, até ali não tem incomodaçãa nenhuma (Luís). 
O bom mesmo no final, que agora eu tô lá, vivendo a vida, maior prazeraço, tenho dinheiro [...]. O bom é assim, quando tá findando [...]. Aí pelo menos tu tá vivendo ali, no finalzinho tá vivendo. Que que é bom no fumo? Só quando tu recebes a grana lá no banco. Quando vem as notas (Leonardo).

Como foi explanado até o momento, os fumicultores trabalham muitas horas por dia. A intensificação do labor em diferentes etapas do ciclo produtivo, como no período de colheita, impossibilita aos profissionais desfrutarem de momentos de lazer. Nas demais épocas da produção, alguns fumicultores verbalizaram poder descansar e aproveitar o tempo livre, e outros não.

Agora mesmo, nós terminemos de colher o fumo. Tá no paiol, mas eu vou começar a classificar. Não tem férias, tamo classificando e já tamo fazendo a muda nova pra próxima safra (Gustavo).

$\mathrm{E}$, às vezes, não tem sábado, não tem domingo. $\mathrm{E}$ ainda o colono tenta tirar o domingo, mas tem época que nem domingo não tem (Fátima).

$\mathrm{Na}$ ótica da maioria desses participantes, ter férias, ir para a praia e ir a um restaurante são realizações impossíveis de serem concretizadas, a não ser que haja alguma opção de lazer próxima a sua casa. "Tem muita gente aqui da cidade, que só conhece Camaquã, porque o hospital daqui é fechado [...]. Quando eu vou, é na casa de um parente" (Pedro). Entretanto alguns produtores explicaram que momentos de lazer são possíveis, desde que o fumicultor consiga organizar sua demanda de trabalho.

Se a semana tem sete dias [...], trabalha os cinco dias. Não vai precisar usar o domingo. Final de semana tem que ser livre pra todo mundo. É só sabê usá a cabeça; usando a cabeça durante a semana, o cara nunca mais trabalha no final de semana (Leonardo).

Um participante descreveu o exemplo de famílias que abdicam de momentos de lazer para adquirir bens e estabilidade. Na percepção desse fumicultor, essas pessoas estão trocando os momentos prazerosos de suas vidas por dinheiro, trabalhando excessivamente.

Lá na minha volta, tem meia dúzia de famílias que são loucos, né, querem dinheiro, dinheiro [...]. Cinco horas da manhã, tão na lavoura. Natal é na lavoura, Páscoa é no galpão. Eles não têm sábado e domingo [...] só que [...] dá pra trocar de carro todos os ano, dá pra compra trator tracionado, $[. .$.$] casa na cidade [\ldots]$. Nunca vão aproveitar [...]; folga, não tem (Daniel).

Como muitos fumicultores submetem-se à intensificação no trabalho, 
desfrutando de poucos momentos de lazer, a sociedade critica aqueles que, paralelamente, procuram gerenciar sua rotina laboral de maneira menos penosa. Os agricultores esclareceram que, em Dom Feliciano, os indivíduos que optam por não viver para o trabalho costumam ser estigmatizados de vagabundos ou preguiçosos.

Eu acho melhor reduzir. Aí dizem, "Mas João, tá de novo aqui em Dom Feliciano". Mas por que que é hein? Eu não posso vir? "Ué, João, mas tu toma chimarrão na lavoura!". Mas o que é que tem? [...] Assim, oh, que nem muita gente diz, "Ah, mas se tu não plantou mais porque tu é vagabundo, tem gente que planta quarenta mil pé, planta feijão, planta milho", ainda tem gente que chama de vagabundo (João).

Conforme Dejours (1992), o prazer no trabalho ocorre quando o sujeito encontra neste uma oportunidade para a sua realização e para a constituição/ construção da sua identidade, reconhecendo a importância da sua atividade laboral para si e para os outros. Segundo os fumicultores que participaram deste estudo, essa realização só se dá ou é validada mediante o justo retorno financeiro por seu trabalho, algo que dificilmente acontece. Na busca pela garantia do lucro esperado com a safra, os participantes referem ter raros momentos de lazer durante o ano.

Alguns fumicultores mencionaram que a participação no estudo foi muito importante e gratificante, uma experiência única, pois os fumicultores não costumam reunirem-se para discutir assuntos de trabalho. Dialogam quase que exclusivamente com seus familiares. "Eu acho que já é um alívio para cada um falar um pouco o que sente. Porque não tem ninguém que te escute, a não ser os de casa ou um grupo quando se junta" (Fátima).

Esses agricultores também expuseram que esta investigação valorizou o seu ponto de vista, oferecendo-lhes a oportunidade de revelar o que sentem e concluíram que precisam criar mais espaços de união e de trocas, por sua iniciativa, pois não acreditam que o Estado mobilizar-se-á nesse sentido.

Considera-se imprescindível que os fumicultores se mobilizem a fim de criarem e espaços de discussão, independentemente da mobilização do Estado. Essa união entre os produtores é fundamental para reverter o quadro de precarização no trabalho e, ou, pensar em outras alternativas viáveis para o sustento das famílias, como a diversificação rural (o emprego de outras modalidades de agronegócio familiar). A mobilização entre os produtores pode ocorrer em associações ou em Centros de Referência em Saúde do Trabalhador (Cerest), no CEREST Regional de Porto Alegre, no caso dos produtores felicianenses, pois o Município de Dom Feliciano/RS está inscrito em sua área de abrangência. 


\section{CONSIDERAÇÕES FINAIS}

Esta pesquisa evidenciou um estado de preocupação constante com a rentabilidade do cultivo do tabaco, estando a gratificação no trabalho associada a dois momentos: ao período do plantio e ao lucro satisfatório com a venda do tabaco. O sofrimento desses agricultores está permeado por um estado constante de preocupação e ansiedade. A busca pela garantia de rentabilidade define o fazer diário dos fumicultores e explica os excessos aos quais se submetem. Expõem-se ao envenenamento e à intensificação do esforço físico para garantir o lucro. $\mathrm{O}$ prazer é desfrutado ao mínimo nessa dinâmica potencialmente adoecedora, em que manter a qualidade das folhas de fumo é mais importante para o agricultor do que preservar sua saúde.

Algumas consequências da dinâmica de sofrimento do cultivo do tabaco foram descritas pelos participantes: o trabalho infantil foi apontado como indispensável, os conflitos familiares como a única alternativa para descarga das pulsões tensionais, o consumo de álcool e de tabaco elencados como estratégias para suportar o sofrimento, o suicídio como alternativa aos fumicultores que precisam dar fim ao seu sofrimento em razão do endividamento.

Este estudo diferenciou-se, portanto, dos estudos de caráter epidemiológico, que discutem principalmente os efeitos deletérios das condiçôes de labor na fumicultura e apontam agravos específicos à saúde dos profissionais: problemas de coluna, câncer e lesões por esforços repetitivos. Por essa razão, optou-se pela PDT como referencial teórico, pois essa abordagem considera que somente o sujeito (no caso, o trabalhador), por meio de sua experiência subjetiva de labor, pode esclarecer quais são os fatores de prazer e de sofrimento no trabalho, possibilitando prevenir o adoecimento físico e psíquico. Nesse sentido, a ferramenta para que possa elaborar o que o trabalho lhe representa é a escuta e a palavra. A participação nos grupos focais permitiu-lhes problematizar suas consideraçôes e a dos demais participantes, significando e ressignificando o sentido do trabalho.

Verificou-se que esses trabalhadores têm sua liberdade de produção cerceada, percebem-se obrigados a ajustarem-se as exigências e determinações das empresas fumageiras. A dita liberdade do homem do campo, como regulador do seu saber-fazer, vem se configurando como uma oportunidade para a intensificação do trabalho. O produtor, como patrão de si, não dá trégua para o esgotamento físico e psíquico.

Esta investigação possibilitou compreender como os fumicultores lidam com as adversidades em seu cotidiano e revelou que muitas crenças e atitudes que eles têm estão pautadas em uma expectativa de lucro. Os fumicultores não 
abandonam o plantio de tabaco porque avaliam que esta ainda é a opção de cultivo mais rentável. Desvelou-se que os agricultores estão totalmente implicados no contexto capitalista e que o seu exercício de labuta vem se apresentando tão operacionalizado quanto o dos operários de fábrica e demais trabalhadores dos centros urbanos.

No que diz respeito à Psicologia, há poucos psicólogos atuando na área rural do Brasil, apesar da necessidade dessa população em receber atenção de profissionais e de equipes de saúde mental. Trata-se de uma iniciativa imprescindível capacitar os psicólogos e ampliar o seu saber clínico, oportunizando um espaço de escuta e de cuidado aos indivíduos e às famílias residentes em localidades rurais. Faz-se necessário conhecer a demanda da população, sempre considerando o contexto em que esta se encontra inscrita. Satisfeito esse critério, como se fez nesta pesquisa, é possível compreender os fatores de sofrimento e de adoecimento dos indivíduos e implantar propostas de prevenção e de promoção de saúde.

Esta pesquisa abre precedentes para estudos que busquem investigar hipóteses diagnósticas quanto ao adoecimento psíquico desses trabalhadores, as quais, segundos os achados desta investigação, está relacionado aos transtornos depressivos e ansiosos desencadeados pela organização do trabalho, acarretando, inclusive, o suicídio de trabalhadores.

Ademais, sugere-se a realização de estudos complementares, a fim de conhecer o impacto da fumicultura para os vínculos familiares, pois, nesse cultivo, como em muitos outros, a equipe de trabalho é o grupo familiar: o marido costuma ser o chefe; a esposa, uma colega de trabalho sobrecarregada; e os filhos, os empregados. O trabalho infantil e a sobrecarga experimentada pela mulher fumicultora, que tem múltiplas tarefas, como cuidar da casa, dos filhos e do plantio, também podem ser objetos de futuras investigações.

Os participantes consideraram a possibilidade dos encontros entre os fumicultores como um importante espaço de troca e de escuta, pois quem planta tabaco não dispõe de tempo para conversar e expressar os sentimentos. Este trabalho evidenciou que os fumicultores precisam não apenas de terem "voz" para que seja lançada sua crítica à sociedade, ao Estado e às fumageiras, mas que se apropriem dessa construção reflexiva, a fim dar outro sentido para o seu trabalho. Apenas o trabalhador pode compreender, desvelar para si, por que deixa de mobilizar sua subjetividade para a satisfação das suas vontades em detrimento das necessidades e desejos da organização do trabalho. Essa é uma conduta alienante e comumente motivada pela organização do trabalho, podendo ser interrompida pelo trabalhador em sua singularidade e potencialidade, em um movimento emancipatório e criador (Merlo, 2003). Espera-se que este estudo 
seja apenas um dentre muitos outros que venham a favorecer o empoderamento dos agricultores, a ajudá-los a perceber que sua participação e união são essenciais para reverter o quadro de precarização em que se encontram, de que o seu sofrimento pode ser criativo e de que podem, sim, voltar a ser protagonistas de sua felicidade. 


\section{REFERÊNCIAS}

Almeida, G. E. E. (2005). Fumo: servidão moderna e violação de direitos humanos. Curitiba: Terra de Direitos.

Arcury, T. A. \& Quandt, S. A. (2006). Health and social impacts of tobacco production. Journal of Agromedicine, 11(3-4), 71-81.

Bardin, L. (1994). Análise de conteúdo. Lisboa: Edições Setenta.

Biernacki, P. \& Waldorf, D. (1981). Snowball sampling: problems and techniques of chain referral sampling. Sociological Methods \& Research, 10(2), 141-163.

Biolchi, M. A. (2005). A cadeia produtiva do fumo. Revista do Departamento de Estudos Socioeconômicos Rurais, 6(5), 1-68.

Dejours, C. (1992). A loucura do trabalho: estudo de psicopatologia do trabalho. São Paulo: Cortez.

Dejours, C. (2004). A metodologia em psicodinâmica do trabalho. In S. Lancman \& L. Sznelwar (Orgs.), Christophe Dejours: da psicopatologia à psicodinâmica do trabalho. (pp. 105-126). Rio de Janeiro: Fiocruz.

Dejours, C. (2007). Psicodinâmica do trabalho na Pós-Modernidade. In A. M. Mendes, S. Lima \& E. P. Facas (Orgs.), Diálogos em psicodinâmica do trabalho. (pp. 13-26). Brasília: Paralelo 15.

Dejours, C. \& Abdoucheli, E. (1993). Desejo ou motivação?: a interrogação psicanalítica do trabalho. In C. Dejours, E. Abdoucheli \& C. Jayet (Orgs.), Psicodinâmica do trabalho: contribuiçôes da escola dejouriana à análise da relação prazer, sofrimento e trabalho. (pp. 33-43, Maria Irene Stocco Betiol, trad.). São Paulo: Atlas.

Dejours, C., Abdoucheli, E. \& Jayet, C. (1993) (Orgs.). Psicodinâmica do trabalho: contribuiçôes da escola dejouriana à análise da relação prazer, sofrimento e trabalho. (M. I. S. Betiol, Trad.). São Paulo: Atlas.

Dejours, C. \& Bègue, F. (2009). Suicídio e trabalho: o que fazer? Brasília: Paralelo 15.

Faria, N. M. X., Facchini, L. A., Fassa, A. C. G\& Tomasi, E. (2001). Processo de produção rural e saúde na serra gaúcha: um estudo descritivo. Cadernos de Saúde Pública, 16, 115-128. 
Fialho, R. R. (2003). Os sentidos produzidos pelos agricultores e agricultoras familiares da cultura de fumo em relação ao trabalho. (Dissertação de Mestrado). Programa de Pós-Graduação em Desenvolvimento Regional, Universidade de Santa Cruz do Sul, Santa Cruz do Sul.

Heemann, F. (2009). O cultivo do fumo e condiçôes de saúde e segurança dos trabalhadores rurais. (Dissertação de Mestrado). Programa de Pós-Graduação em Engenharia de Produção, Universidade Federal do Rio Grande do Sul, Porto Alegre.

Heloani, J. R. \& Capitão, C. G. (2003). Saúde mental e psicologia do trabalho. São Paulo Perspectiva, 17(2), 102-108.

Heloani, J. R. \& Lancman, S. (2004). Psicodinâmica do trabalho: o método clínico de intervenção e investigação. Produção, 14(3), 77-86.

Hillesheim, B. (2001). O trabalho e infância na vida de meninos e meninas trabalhadores (as) em lavouras de fumo. (Dissertação de Mestrado). Programa de Pós-Graduação em Psicologia Social e da Personalidade, Pontifícia Universidade Católica do Rio Grande do Sul, Porto Alegre.

Instituto Brasileiro de Geografia e Estatística [IBGE] (2010). Informaçōes estatísticas do Município de Dom Feliciano. Rio de Janeiro: IBGE. Recuperado a partir de http://www.ibge.gov.br/cidadesat/xtras/temas.php? codmun=430 650\&idtema=1\&search=rio-grande-do-sul|dom-feliciano|2010-populationcensus:-synopsis-

Instituto Nacional de Câncer [INCA] (2010). Brasil defende proibição de aditivos no cigarro em reunião internacional. Rio de Janeiro: Inca. Recuperado a partir de http://www2.inca.gov.br/wps/wcm/connect/agencianoticias/site/ home/noticias/2010/brasil_defende_proibicao_aditivos_cigarro_reuniao_ internacional

Martins, S. R. (2009). Clínica do Trabalho. São Paulo: Casa do Psicólogo.

Martins, S. R. \& Mendes, A. M. (2012). Coletivo de discussão: a clínica psicodinâmica do trabalho como ação de resistência. Revista Psicologia: Organizaçōes e Trabalho, 12(2), 171-184.

Mendes, A. M. \& Araújo, L. K. R. (2011). A perspectiva da psicodinâmica do trabalho sobre a prática da clínica do trabalho em instituições brasileiras. In J. C. Zanelli, N. Silva \& S. R. Tolfo (Orgs.). Processos psicossociais nas organizaçōes e no trabalho. (pp. 9-435). São Paulo: Casa do Psicólogo. 
Merlo, A. R. C. (2003). Psicodinâmica do trabalho. In M. G. Jacques \& W. Codo (Orgs.), Saúde mental \& trabalho: leituras. (pp. 130-142). Petrópolis: Vozes.

Merlo, A. R. C. \& Mendes, A. M. B. (2007). Perspectivas do uso da psicodinâmica do trabalho no Brasil: teoria, pesquisa e ação. Cadernos de Psicologia Social e do Trabalho, 12(2), 141-156.

Peres, F. \& Moreira, J. C. (2003). É veneno ou é remédio?: agrotóxicos, saúde e ambiente. Rio de Janeiro: Fiocruz.

Pires, D. X., Caldas, E. D. \& Recena, M. C. P. (2005). Uso de agrotóxicos e suicídios no estado do Mato Grosso do Sul, Brasil. Caderno de Saúde Pública, 21 (2), 598-605.

Resolução 16/2000. (2000). Resolução para pesquisa com seres humanos. Brasília: Conselho Federal de Psicologia.

Resolução 196/1996. (1996). Diretrizes e normas regulamentadoras de pesquisas envolvendo seres humanos. Brasília: Conselho Nacional de Saúde.

Rocha Júnior, D. S., Botelho, J. O. B., Fiol, F. S. \& Oshima-Franco, Y. (2004). Síndromes neurológicas induzidas por praguicidas organofosforados e a relação com o suicídio. Saúde em Revista, 6 (14), 53-60.

Santos Junior, A. V., Mendes, A. M. \& Araújo, L. K. R. (2009). Experiência em clínica do trabalho com bancários adoecidos por LER/DORT. Psicologia Ciência e Profissão, 29(3), 614-625.

Schlindwein, V. L. D. C. (2010). Dor e sofrimento oculto: a desproteção social dos trabalhadores do fumo. Barbarói, 32(1), 82-97.

Schmitt, N. M., Schmitt, J., Kouimintzis, D. J. \& Kirch, W. (2007). Health risks in tobacco farm workers: a review of the literature. Journal of Public Health, 15 (4), 255-264.

Silva, A. R. (2007). O significado do trabalho na terra do fumo: perspectivas dos agricultores frente ao sistema integrado de produção industrial em Santa Cruz do Sul/RS. (Dissertação de Mestrado). Programa de Pós-Graduação em Desenvolvimento Regional, Universidade de Santa Cruz do Sul, Santa Cruz do Sul. 
Silva, S. S. \& Ferreira, P. A. (2006). A fumicultura no Brasil: um estudo exploratório sobre os impactos da Convenção-Quadro para o controle do tabaco e o posicionamento do Governo Federal [Resumo]. In Anais do 26 Encontro Nacional de Engenharia de Produção ENEGEP. Fortaleza: Abepro.

Trad, L. A. B. (2009). Grupos focais: conceitos, procedimentos e reflexões baseadas em experiências com o uso da técnica em pesquisas de saúde. Physis Revista de Saúde Coletiva, 19(3), 777-796.

Troian, A. \& Eichler, M. L. (2009). "Somente os mais fracos ficam doentes": a utilização de agrotóxicos por agricultores de tabaco da Comunidade Cândido Brum, em Arvorezinha (RS). Gestão e Desenvolvimento Regional, 5(3), 116139.

Troian, A., Oliveira, S. V., Dalcin, D. \& Eichler, M. L. (2009). O uso de agrotóxicos na produção de fumo: algumas percepções de agricultores da comunidade Cândido Brum, no Município de Arvorezinha (RS) [Resumo]. In Anais do 47 Congresso da Sociedade Brasileira de Economia, Administração e Sociologia Rural - Sober. Porto Alegre: Sober.

Vargas, M. A. \& Oliveira, B. F. (2012). Estratégias de diversificação em áreas de cultivo de tabaco no Vale do Rio Pardo: uma análise comparativa. Revista de Economia e Sociologia Rural, 50(1), 175-192.

Vasconcelos, A. \& Faria, J. H. (2008). Saúde mental no trabalho: contradições e limites. Revista Psicologia \& Sociedade, 20(3), 453-464. 